\title{
Rendimentos de carcaça, dos cortes comerciais e da porção comestível de bubalinos Murrah castrados abatidos com diferentes períodos de confinamento ${ }^{1}$
}

\author{
Paulo Francisco Nogueira Bomfim Ferreira Menegucci ${ }^{2}$, André Mendes Jorge ${ }^{3}$, Cristiana \\ Andrighetto $^{4}$, Natália Bortoleto Athayde ${ }^{5}$, Caroline de Lima Francisco ${ }^{5}$, \\ Érico Rodrigues ${ }^{6}$, Sílvia Maria Marinho Storti ${ }^{6}$
}

\footnotetext{
1 Parte da dissertação do primeiro autor apresentada ao Programa de Pós-Graduação em Zootecnia pela FMVZ/UNESP-Botucatu-SP.

2 Mestre em Zootecnia pela FMVZ/NESP-Botucatu-SP.

${ }^{3}$ Departamento de Produção Animal, FMVZ/UNESP-Botucatu-SP. Pesquisador do CNPq.

${ }^{4}$ Doutoranda em Zootecnia, FMVZ/UNESP/Botucatu-SP.

${ }^{5}$ Graduando em Zootecnia. FMVZ/UNESP-Botucatu. Bolsista do CNPq-PIBIC.

${ }^{6}$ Mestrando em Zootecnia, FMVZ/UNESP-Botucatu-SP.
}

RESUMO - Avaliaram-se as características de carcaça de búfalos Murrah castrados terminados em confinamento. Foram utilizados 20 bubalinos Murrah ( 15 meses de idade e peso inicial de $207 \mathrm{~kg}$ ), castrados e descornados, divididos em quatro grupos homogêneos e abatidos aos 75, 100, 125, 150 dias de confinamento, após período de adaptação. Ao abate, as carcaças foram identificadas, resfriadas por 24 horas para pesagem e cálculo dos rendimentos das meias-carcaças, dos cortes dianteiro, pontade-agulha, traseiro total e serrote. Não houve diferença estatística para o rendimento de carcaça. Os pesos de traseiro total, serrote e dianteiro apresentaram aumento linear, porém, observou-se efeito cúbico do período de confinamento sobre os rendimentos de traseiro total e dianteiro. Verificou-se ainda aumento linear dos pesos de filé-mignon, contrafilé, fraldinha, coxão mole, coxão duro, lagarto, sebo, porção comestível e ossos. O período de confinamento promoveu efeito linear decrescente sobre os rendimentos de patinho, músculo traseiro e maminha + alcatra e linear crescente para fraldinha e sebo.

Palavras-chave: búfalos de rio, carcaça, cortes primários, porcentagem, traseiro

\section{Yields of carcass, retail cuts and retail beef cuts of castrated Murrah buffaloes slaughtered at different periods of feedlot}

\begin{abstract}
The objective of this trial was to evaluate the carcass traits of feedlot castrated Murrah buffaloes. Twenty castrated hornless Murrah buffaloes averaging 15 months of age and initial body weight of $207 \mathrm{~kg}$ were used. Animals were divided in four groups and slaughtered at 75, 100, 125 or 150 days of feedlot after an adaptation period. At slaughter, carcasses were identified, cooled for 24 hours, and weighed for calculation of yields of half carcass, hindquarter, spare ribs, forequarter, and sawcut. There was no significant difference for carcass yield comparing the different periods of feedlot. Weights of sawcut, forequarter, hindquarter, tenderloin, strip loin, thin skirt, topside, outside flat, eye round, tallow, retail beef cuts, and bones all increased linearly while significant cubic effects were observed for yields of forequarter and hindquarter by increasing the days in feedlot. However, yields of knuckle, shank, and beef loin + tri-tip decreased linearly while those of thin skirt and tallow increased linearly when the feedlot period went from 75 to 150 days.
\end{abstract}

Key Words: carcass, hindquarter, percentage, primal cuts, water buffalo

\section{Introdução}

A bubalinocultura de corte é uma atividade que tem conquistado cada vez mais espaço na pecuária de corte brasileira, principalmente em virtude da boa adaptabilidade desses animais aos trópicos (Jorge \& Andrighetto, 2005). Portanto, é importante o fomento dessa atividade no Brasil, mas, para que conquiste a preferência dos consumidores, a carne bubalina deve ser proveniente de animais jovens, que possuem carne mais macia e com menor teor de gordura.

A melhora na qualidade da carne inclui a correta utilização de tecnologias disponíveis ao produtor e de sistemas alimentares para redução da idade ao abate, como os confinamentos (Restle \& Vaz et. al, 1999; Vaz et. al, 2003).

Os bubalinos, quando terminados em confinamento, possuem bom potencial para produção de carcaça com bons rendimentos de cortes comerciais(Franzolin \& Silva, 
2001). A avaliação do rendimento de carcaça e dos cortes do traseiro especial ou ponta-de-agulha é fundamental, visto que esses cortes são os mais utilizados nos frigoríficos e açougues para comercialização (Jorge, 1999).

O rendimento de carcaça de animais de diferentes raças depende diretamente dos pesos de couro, cabeça e trato gastrintestinal (Jorge, 1999). Outros fatores que também podem influenciar o rendimento de carcaça são genética, nutrição e sexo (Franzolin \& Silva, 2001).

Em termos econômicos, é desejável maior rendimento de traseiro especial em relação aos outros cortes, pois nele se encontram as partes nobres, com maior valor comercial da carcaça, daí a importância da avaliação desses cortes na cadeia produtiva de carne bubalina (Jorge et al., 2003). Entretanto, com o avançar da idade dos animais, a proporção entre os cortes se altera, diminuindo a de traseiro especial (Luchiari Filho, 2000).

Alguns pesquisadores relatam que animais castrados apresentam maior rendimento de traseiro, onde se encontram os cortes nobres de maior valor comercial, todavia, esses animais possuem menor peso da carcaça (Restle et al., 2000; Rodrigues et al, 2003).

O número reduzido de trabalhos sobre bubalinos de corte favorece a estigmatização da espécie, considerada tardia, com baixos rendimentos de cortes e de carcaça. Esse conceito se justifica pelo fato de os dados serem provenientes de animais velhos, criados em sistemas totalmente desfavoráveis à espécie, com pastagem de baixa qualidade e suplementação insuficiente para atender às exigências dos animais (Calixto, 2004).

Este trabalho foi realizado com o objetivo de avaliar os rendimento de carcaça e dos cortes primários comerciais de búfalos Murrah castrados terminados em diferentes períodos de confinamento.

\section{Material e Métodos}

O experimento a campo foi conduzido no confinamento experimental do Departamento de Nutrição e Melhoramento Animal da Faculdade de Medicina Veterinária e Zootecnia,UNESP, Campus de Botucatu - SP.

Foram utilizados 20 bubalinos machos Murrah (idade inicial de 15 meses e peso inicial de $207 \mathrm{~kg}$ ) provenientes de um rebanho leiteiro, castrados aos 12 meses e descornados na primeira semana após o nascimento. Os animais foram divididos em quatro grupos e abatidos aos $75,100,125 \mathrm{ou}$ 150 dias de confinamento, após período de adaptação.

O período de adaptação à dieta, ao manejo e às instalações experimentais foi de 28 dias. Antes do período de adaptação, os animais foram identificados com brincos plásticos numerados e receberam anti-helmíntico e 1.500.000 UI de complexo vitamínico ADE. Posteriormente, foram distribuídos aleatoriamente em grupos de cinco animais e alocados em quatro baias $(10 \times 30 \mathrm{~m})$ com bebedouro tipo australiano, com capacidade para $1.500 \mathrm{~L}$.

A dieta foi fornecida ad libitum, em duas refeições diárias, $40 \%$ às $8 \mathrm{~h}$ e os $60 \%$ restantes às $6 \mathrm{~h}$, de modo que as sobras dos cochos, em um período de 24 horas, atingissem 5 a $10 \%$ da MS fornecida.

As dietas foram formuladas com base no NRC (1996), considerando-se as exigências para animais castrados em crescimento com ganho de peso diário de $1,20 \mathrm{~kg} / \mathrm{dia}$. A relação volumoso:concentrado utilizada foi de 30:70 e os alimentos utilizados nas rações foram feno de Brachiaria decumbens, silagem de milho, caroço de algodão, polpa cítrica, silagem de milho grão úmido e minerais, conforme descrito na Tabela 1.

Durante o período experimental, a cada 28 dias, foram realizadas pesagens dos animais, sempre antes da primeira refeição do dia e com jejum de sólidos de 16 horas, para monitoração do ganho de peso médio diário e ajuste das dietas. A cada pesagem, calculou-se o peso médio dos lotes e efetuaram-se os ajustes do consumo de MS.

Após os períodos de permanência pré-estabelecidos no confinamento, os animais foram abatidos, em jejum de sólidos (16 horas), em frigorífico comercial localizado a $40 \mathrm{~km}$ do confinamento experimental. Ao abate, as carcaças foram identificadas e resfriadas por 24 horas a $2^{\circ} \mathrm{C}$, sendo pesadas individualmente e divididas em duas metades, com auxílio de serra elétrica.

Depois de resfriadas, as meias-carcaças direitas foram divididas em dianteiro, traseiro total (secção entre a $5 \underline{a}$ e a 6 a costela) e ponta-de-agulha, a aproximadamente $22 \mathrm{~cm}$ da coluna vertebral, segundo as normas do frigorífico. Foram pesados os cortes dianteiro, ponta-de-agulha, traseiro total e serrote. Logo após a realização dos cortes primários, o serrote direito foi desossado e os cortes comerciais

Tabela 1 - Composição da dieta experimental, com base na MS Table 1 - Ingredient composition of the experimental diet, \% of DM

Ingrediente MS (\%)

Ingredient $D M(\%)$

Silagem de milho (Corn silage)

11,54

Feno de coastcross (Coast cross hay)

16,14

Caroço de algodão (Whole cottonseed)

3,50

Polpa cítrica peletizada (Citrus pulp pellets)

10,10

Silagem de milho úmido (High moisture corn)

46,56

Concentrado (Nutrumin ${ }^{\circledR}$ )

12,16

Commercial concentrate (Nutrumin ${ }^{\circledR}$ )

PB $(\%)(C P, \%)$

15,00

EM (Mcal/kg) (ME, Mcal/kg) 
submetidos à pesagem para cálculo dos rendimentos. $\mathrm{O}$ rendimento de carcaça fria foi determinado em função do peso vivo obtido na fazenda após 16 horas de jejum. Foram determinados também os rendimentos dos cortes primários em função do peso da carcaça fria e dos cortes comerciais do serrote em função do peso do serrote.

$\mathrm{O}$ delineamento experimental adotado foi o inteiramente ao acaso, com quatro tratamentos e cinco repetições. Para a análise estatística, primeiramente efetuou-se uma triagem pela análise de variância multivariada (MANOVA) para os parâmetros estudados. Estimado o efeitosignificativo para algumas das características analisadas, aplicou-se análise de regressão para cada uma das variáveis, determinando-se ainda as correlações de Pearson dos parâmetros avaliados. As análises foram processadas pelo programa SAS (1993).

O modelo estatístico utilizado foi:

$$
Y_{i j}=B_{0}+B_{1} P_{i j}+B_{2} P^{2}{ }_{i j}+E_{i j},
$$

em que: $Y_{i j}=$ variáveis dependentes; $B_{0}, B_{1}, B_{2}=$ parâmetros $\mathrm{da}$ equação a serem estimados, $\mathrm{PC}=$ período $\mathrm{de}$ confinamento na repetição $j$ do tratamento $i$, sendo $i=1(75$ dias); $\mathrm{i}=2$ (100 dias); $\mathrm{i}=3$ (125 dias) e $\mathrm{i}=4$ (150 dias); $\mathrm{E}_{\mathrm{ij}}=$ erro experimental da observação.

\section{Resultados e Discussão}

Na Tabela 2 constam as equações de regressão e os coeficientes de determinação para o peso de abate, o ganho de peso, o peso da carcaça fria, o peso e os rendimentos de cortes primários e da carcaça fria.

Observou-se aumento linear $(\mathrm{P}<0,05)$ dos pesos de abate, de carcaça fria e dos cortes primários, à exceção da ponta-de-agulha. Os períodos de confinamento pré-estabelecidos proporcionaram aumento linear $(\mathrm{P}<0,05)$ nos pes os de abate, o que influenciou os pesos de carcaça fria, de dianteiro, traseiro total e serrote, mas não alterou os rendimentos de carcaça fria, serrote e ponta-de-agulha.

Os valores para o peso da carcaça fria estão de acordo com os encontrados na literatura, que variam de 179,9 a 246,2 kg (Mattos et al., 1997; Franzolin \& Silva, 2001; Vaz et al., 2003; Rodrigues et al., 2003; Calixto, 2004).

Os pesos dos cortes primários foram inferiores aos encontrados por Calixto, (2004) e Jorge et. al. (1997), em bubalinos de corte Mediterrâneo. Calixto (2004) observou variações de 40,1 a 47,4 kg para peso de dianteiro e de 55,63 a $65,10 \mathrm{~kg}$ para peso de serrote, enquanto Mattos et al. (1997) relataram variações de 94,83 a $102,71 \mathrm{~kg}$ para peso do

Tabela 2 - Médias e equações de regressão para peso de abate $(\mathrm{kg})$, peso da carcaça fria $(\mathrm{kg})$, ganho peso (kg), peso e rendimento de cortes primários de bubalinos Murrah castrados abatidos em diferentes períodos de confinamento

Table 2 - Means and regression equations for slaughter weight ( $\mathrm{kg}$ ), cold carcass weight ( $\mathrm{kg}$ ), body weight gain ( $\mathrm{kg}$ ), weight and yield of primary cuts of castrated Murrah buffaloes slaughtered at different periods of feedlot

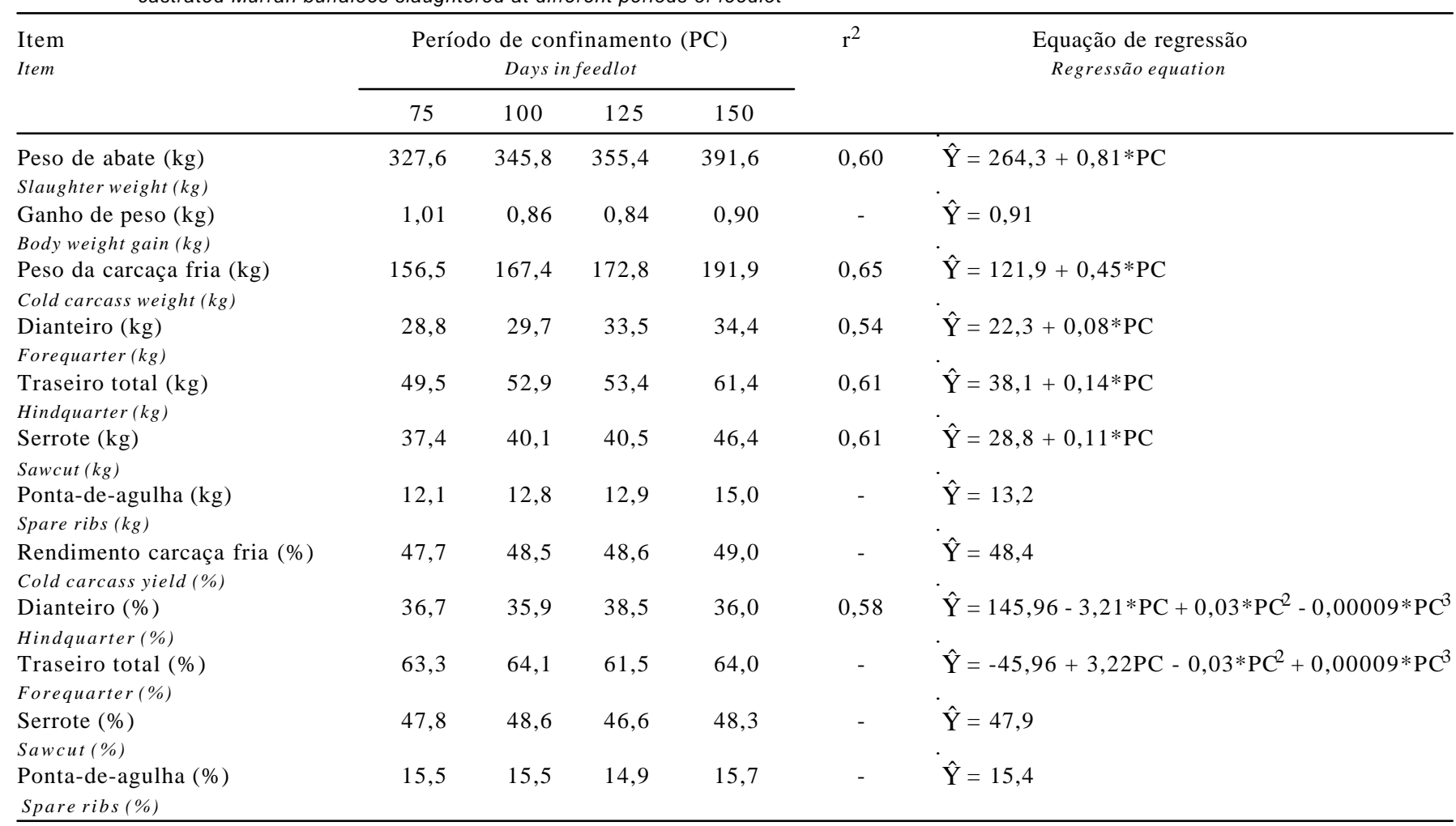


traseiro total. Os baixos pesos dos cortes primários neste estudo podem estar relacionados ao baixo peso de abate obtido aos 150 dias de confinamento (em média $391,6 \mathrm{~kg}$ ) ou à origem dos animais, provenientes de rebanho leiteiro.

Não houve diferença no ganho de peso diário dos animais abatidos nos diferentes períodos de confinamento. $\mathrm{O}$ valor médio de ganho de peso diário verificado neste estudo $(0,91 \mathrm{~kg} / \mathrm{dia})$ foi inferior ao obtido por Calixto (2004) em bubalinos de corte Mediterrâneo não-castrados (1,35 kg/dia), e por Jorge et al. (1997), também em animas Mediterrâneo, linhagem de corte $(1,3 \mathrm{~kg} / \mathrm{dia})$, abatidos em diferentes estádios de maturidade. O menor ganho de peso afetou o desenvolvimento dos animais, pois esperava-se que aos 150 dias de confinamento atingissem aproximadamente $450 \mathrm{~kg}$ de PV. Provavelmente, esse menor ganho de peso resultou do fato de os animais serem castrados e provenientes de rebanho leiteiro, onde não sofrem seleção para produção de carne e, muitas vezes, recebem poucas quantidades de leite, visto que o leite, nesse caso, é a principal fonte de renda para o produtor.

O número de dias em confinamento não proporcionou $(\mathrm{P}>0,05)$ aumento linear no rendimento carcaça fria dos animais - o rendimento médio encontrado foi de $48,4 \%$. Segundo Faturi et al. (2002), o rendimento de carcaça é influenciado pela taxas de passagem da dieta. Os rendimentos de carcaça observados neste estudo durante os vários períodos de confinamento corroboram essa afirmação, pois todos os abates foram realizados após jejum de sólidos de 16 horas, observando-se que os animais eram de mesma raça e foram submetidos à mesma dieta durante todo o período experimental.

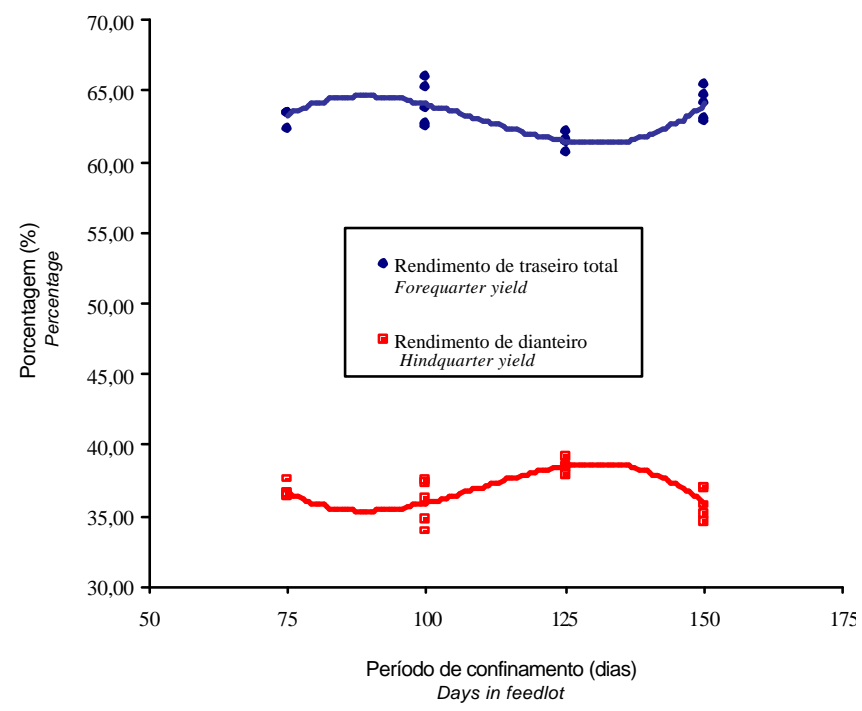

Figura 1 - Rendimentos de traseiro total e dianteiro de bubalinos Murrah castrados abatidos em diferentes períodos de confinamento.

Figure 1 - Yields of forequarter and hindquarter of castrated Murrah buffaloes slaughtered at different periods of feedlot.
Os rendimentos de carcaça $(48,4 \%)$ foram semelhantes aos registrados por Macedo et al. (2000), em bubalinos Mediterrâneos castrados terminados em pastagem (49,2\%); por Vazet al. (2003) (49,9\%); e Calixto (2004), em estudo com animais Mediterrâneos não-castrados (49,6\%). Por outro lado, foram inferiores aos $51,3 \%$ obtidos por Jorge et al. (2002), em bubalinos de corte (Mediterrâneo) castrados.

Quanto ao rendimento dos cortes primários, apenas o dianteiro e o traseiro total apresentaram efeito cúbico (Tabela 2). O rendimento desses dois cortes teve comportamento de crescimento oposto durante os períodos de confinamento estudados (Figura 1); aos 150 dias de confinamento, observou-se queda no rendimento de dianteiro e aumento no rendimento de traseiro total, o que, segundo Rodrigues et al. (2003), ocorre porque a supressão dos testículos acarreta regressão dos caracteres sexuais secundários, ocasionando menor desenvolvimento do quarto dianteiro (cabeça, pescoço, acém e peito) e, conseqüentemente, maior rendimento do traseiro total.

Os rendimentos de dianteiro $(36,8 \%)$ e serrote $(47,9 \%)$ neste estudo foram inferiores aos encontrados por Jorge et al. (2002), de 39,0\% para dianteiro e $49,1 \%$ para serrote em búfalos Mediterrâneos castrados. Estes mesmos autores encontraram valores inferiores ao encontrado neste estudo para ponta-de-agulha $(11,9 \%)$ e traseiro total $(61,0 \%)$.

Quando avaliaram machos de corte não-castrados da raça Mediterrâneo abatidos aos $400 \mathrm{~kg}$ de PV, Jorge et al. (2003) obtiveram valores de rendimento superiores para dianteiro $(41,1 \%)$, inferiores para ponta-de-agulha $(12,0 \%)$ e traseiro total $(58,2 \%)$ e similares para serrote $(47,7 \%)$ em relação aos observados neste estudo.

Como demonstrado na Tabela 3 , os pesos de filé-mignon, contrafilé, fraldinha, lagarto, coxão mole, coxão duro, sebo, porção comestível e ossos sofreram incremento linear positivo em função do período de confinamento. A porção comestível e os ossos apresentaram aumentos diários de 0,0647 e $0,044 \mathrm{~kg}$, respectivamente, durante o confinamento.

Trabalhando com bubalinos de corte Mediterrâneo nãocastrados e abatidos com diferentes pesos $(450,480,510$ e $540 \mathrm{~kg}$ ), Calixto (2004) encontrou valores para peso dos cortes comerciais superiores aos deste estudo. Jorge (1999), no entanto, observou valor semelhante para peso do patinho (3,6 kg) em búfalos da raça Mediterrâneo abatidos aos $450 \mathrm{~kg}$, mas, para os demais cortes comerciais, os resultados encontrados por esse autor foram superiores aos obtidos neste estudo. Ressalta-se que os últimos animais deste estudo foram abatidos com pesos bem inferiores (391,6 kg) aos descritos por Calixto (2004) e Jorge (1999), o que contribuiu para os menores pesos dos cortes comerciais do serrote. 
Tabela 3 - Médias e equações de regressão para peso dos cortes comerciais do serrote de bubalinos Murrah castrados abatidos em diferentes períodos de confinamento

Table 3 - Means and regression equations for weight of the commercial cuts from the pistola cut of castrated Murrah buffaloes slaughtered at different periods of feedlot

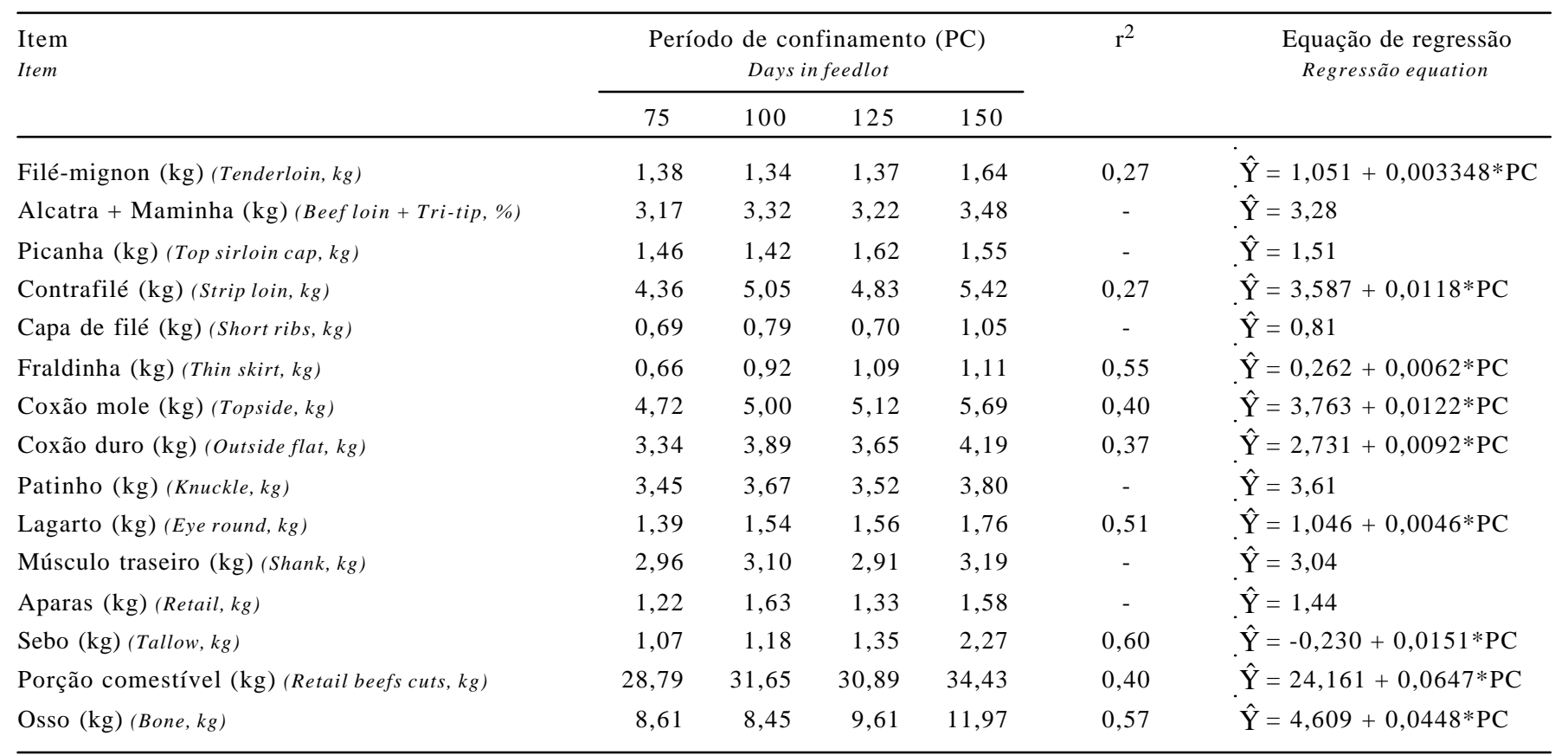

Tabela 4 - Médias e equações de regressão para rendimento dos cortes comerciais do serrote de bubalinos Murrah castrados abatidos em diferentes períodos de confinamento

Table 4 - Means and regression equations for yield of commercial cuts from pistola cut of castrated Murrah buffaloes slaughtered at different periods of feedlot

\begin{tabular}{|c|c|c|c|c|c|c|}
\hline \multirow[t]{2}{*}{$\begin{array}{l}\text { Item } \\
\text { Item }\end{array}$} & \multicolumn{4}{|c|}{$\begin{array}{l}\text { Período de confinamento (PC) } \\
\text { Days in feedlot }\end{array}$} & \multirow[t]{2}{*}{$r^{2}$} & \multirow[t]{2}{*}{$\begin{array}{l}\text { Equação de regressão } \\
\text { Regressão equation }\end{array}$} \\
\hline & 75 & 100 & 125 & 150 & & \\
\hline Filé-mignon (\%) (Tenderloin, \%) & 3,67 & 3,32 & 3,38 & 3,53 & - & $\hat{Y}=3,47$ \\
\hline Alcatra + Maminha $(\%)($ Beefloin + Tri-tip, $\%)$ & 8,45 & 8,27 & 7,94 & 7,49 & 0,38 & $\hat{\mathrm{Y}}=9,492-0,0129 * \mathrm{PC}$ \\
\hline Picanha (\%) (Top sirloin cap, \%) & 3,91 & 3,55 & 3,99 & 3,44 & - & $\hat{Y}=3,72$ \\
\hline Capa de filé (\%) (Short ribs, \%) & 1,85 & 1,95 & 1,73 & 2,25 & - & $\hat{\mathrm{Y}}=1,95$ \\
\hline Fraldinha $(\%)$ (Thin skirt, \%) & 1,76 & 2,29 & 2,67 & 2,39 & 0,31 & $\hat{\mathrm{Y}}=1,258+0,00907 * \mathrm{PC}$ \\
\hline Coxão mole (\%) (Topside, \%) & 12,60 & 12,46 & 12,64 & 12,27 & - & $\hat{Y}=12,49$ \\
\hline Coxão duro (\%) (Outside flat, \%) & 8,92 & 9,69 & 9,02 & 9,01 & - & $\hat{\mathrm{Y}}=9,16$ \\
\hline Patinho (\%) (Knuckle, \%) & 9,24 & 9,14 & 8,67 & 8,16 & 0,45 & $\hat{\mathrm{Y}}=10,464-0,0148 * \mathrm{PC}$ \\
\hline Sebo $(\%)($ Tallow, \%) & 2,87 & 2,92 & 3,30 & 4,90 & 0,53 & $\hat{\mathrm{Y}}=0,588+0,0258 * \mathrm{PC}$ \\
\hline Porção comestível (\%) (Retail beefs cuts, \%) & 79,78 & 81,84 & 79,54 & 79,09 & - & $\hat{Y}=80,06$ \\
\hline Osso $(\%)($ Bone, $\%)$ & 20,22 & 18,16 & 20,46 & 20,91 & - & $\hat{Y}=19,94$ \\
\hline
\end{tabular}

Houve efeito linear negativo $(\mathrm{P}<0,05)$ do período de confinamento sobre os rendimentos de alcatra + maminha, patinho e músculo traseiro (Tabela 4), ou seja, com o aumento do período de confinamento, a porcentagem desses cortes reduziu (os maiores valores foram registrados aos 75 dias de confinamento). Por outro lado, verificou-se efeito linear positivo $(\mathrm{P}<0,05)$ do período de confinamento sobre os rendimentos de fraldinha e sebo.

Com o aumento do período de confinamento e, conseqüentemente, do peso dos animais, espera-se maior desenvolvimento do tecido adiposo, o que, no caso deste estudo, foi explicado pelo maior rendimento de sebo aos 150 diasde 
confinamento, sendo que o aumento foi em torno de $0,0258 \%$ por dia de confinamento.

Os resultados obtidos para rendimento de cortes comerciais do serrote foram inferiores aos encontrados por Calixto (2004), em experimento com bubalinos de corte Mediterrâneo não-castrados abatidos com diferentes pesos (450, 480, 510 e $540 \mathrm{~kg}$ ), fato explicado principalmente pelos menores pesos de abate e pela origem leiteira dos animais deste estudo.

Franzolin \& Silva (2001), avaliando diferentes níveis de energia na dieta de bubalinos Mediterrâneo (baixa, média e alta), observaram valores de rendimento dos cortes do serrote, à exceção da fraldinha $(2,1 \%)$, superiores aos obtidos neste estudo.

As correlações de Pearson $(\mathrm{P}<0,05)$ para as variáveis estudadas são apresentadas na Tabela 5 . O peso da carcaça fria apresentou correlação positiva e significativa $(\mathrm{P}<0,05)$ com os pesos de traseiro total $(r=0,98)$, serrote $(r=0,88)$, dianteiro $(\mathrm{r}=0,88)$, ponta-de-agulha $(\mathrm{r}=0,61)$ e osso do serrote $(\mathrm{r}=0,58)$ e com os rendimentos de carcaça fria $(r=0,42)$ e traseiro total $(r=0,39)$ e correlação negativa e significativa $(\mathrm{P}<0,05)$ para dianteiro $(\mathrm{r}=-0,39)$. Para o rendimento de carcaça, no entanto, observaram-se correlações positivas $(\mathrm{P}<0,05)$ entre os pesos de dianteiro, de traseiro e da porção comestível do serrote.

Vaz et al. (2003), trabalhando com bubalinos Mediterrâneo não-castrados, encontraram correlação positiva e significativa $(\mathrm{P}<0,05)$ entre peso da carcaça fria e rendimento da carcaça fria $(r=0,76)$. Calixto (2004), em estudo com bubalinos Mediterrâneo abatidos em diferentes idades, também observou correlação positiva e significativa $(\mathrm{P}<0,05)$ entre essas duas variáveis $(\mathrm{r}=0,44)$. A correlação dessas duas variáveis foi comentada por Preston \& Willis (1974), que afirmaram que o rendimento de carcaça aumenta com o incremento do peso de abate e a deposição de gordura da carcaça.

A correlação para os pesos de carcaça fria e de traseiro total está de acordo com a obtida por Costa et al. (2002)

Tabela 5 - Coeficientes de correlação de Pearson entre peso e rendimento da carcaça fria e entre peso e rendimento de cortes primários e comerciais de bubalinos Murrah castrados abatidos em diferentes períodos de confinamento

Table 5 - Pearson correlations coefficients between weight and yield of cold carcass, weight and yield of primary and comercial cuts of castrated Murrah buffaloes slaughtered at different periods of feedlot

\begin{tabular}{|c|c|c|c|c|c|c|c|c|c|c|c|c|c|c|}
\hline Item & $\begin{array}{l}\mathrm{PCF} \\
\mathrm{CCW}\end{array}$ & $\begin{array}{l}\mathrm{PTT} \\
\text { FOW }\end{array}$ & $\begin{array}{c}\text { PsE } \\
P S C W\end{array}$ & $\begin{array}{l}\text { PDI } \\
H I W\end{array}$ & $\begin{array}{c}\text { PPT A } \\
S R W \\
\end{array}$ & $\begin{array}{l}\text { PPCOSE } \\
R B C P S C W\end{array}$ & $\begin{array}{c}\text { POSE } \\
B P S C W \\
\end{array}$ & $\begin{array}{r}\mathrm{RCF} \\
C C Y \\
\end{array}$ & $\begin{array}{l}\mathrm{RTT} \\
F O Y \\
\end{array}$ & $\begin{array}{l}\text { RSE } \\
P S C Y\end{array}$ & $\begin{array}{c}\text { RDI } \\
H I Y\end{array}$ & $\begin{array}{c}\text { RPTA } \\
S R Y \\
\end{array}$ & $\begin{array}{l}\text { RPCOSE } \\
R B C P S C Y\end{array}$ & $\begin{array}{l}\text { ROSE } \\
\text { BPSCY }\end{array}$ \\
\hline $\begin{array}{l}\text { PCF } \\
C C W\end{array}$ & - & & & & & & & & & & & & & \\
\hline $\begin{array}{l}\mathrm{PTT} \\
\text { FOW }\end{array}$ & $0,98 *$ & - & & & & & & & & & & & & \\
\hline $\begin{array}{l}\text { PTE } \\
P S C W\end{array}$ & $0,88^{*}$ & $0,87^{*}$ & - & & & & & & & & & & & \\
\hline $\begin{array}{l}\text { PDI } \\
H I W\end{array}$ & $0,88^{*}$ & $0,80 *$ & $0,72 *$ & - & & & & & & & & & & \\
\hline $\begin{array}{l}\text { PPTA } \\
S R W\end{array}$ & $0,61 *$ & $0,66^{*}$ & 0,22 & $0,51 *$ & - & & & & & & & & & \\
\hline $\begin{array}{l}\text { PPCOSE } \\
R B C P S C W\end{array}$ & 0,30 & $0,84^{*}$ & $0,92 *$ & $0,70^{*}$ & 0,26 & - & & & & & & & & \\
\hline $\begin{array}{l}\text { POTE } \\
B P S C W\end{array}$ & $0,58 *$ & $0,60 *$ & $0,76^{*}$ & $0,48 *$ & 0,06 & $0,46^{*}$ & - & & & & & & & \\
\hline $\begin{array}{l}\mathrm{RCF} \\
C C Y\end{array}$ & $0,42 *$ & 0,33 & $0,44^{*}$ & $0,52 *$ & 0,001 & $0,51 *$ & 0,15 & - & & & & & & \\
\hline $\begin{array}{l}\mathrm{RTT} \\
\text { FOY }\end{array}$ & $0,39 *$ & 0,23 & 0,18 & $-0,40 *$ & 0,19 & 0,16 & 0,15 & $-0,32$ & - & & & & & \\
\hline $\begin{array}{l}\text { RSE } \\
P S C Y\end{array}$ & 0,23 & 0,06 & 0,24 & $-0,37$ & $-0,24$ & 0,12 & 0,36 & $-0,27$ & $0,71 *$ & - & & & & \\
\hline $\begin{array}{l}\text { RDI } \\
H I Y\end{array}$ & $-0,39 *$ & $-0,23$ & $-0,18$ & $0,40^{*}$ & $-0,19$ & $-0,16$ & $-0,15$ & 0,32 & $-1,00 *$ & $-0,71 *$ & - & & & \\
\hline $\begin{array}{l}\text { RPTA } \\
P C Y\end{array}$ & 0,23 & $0,67 *$ & 0,22 & $0,51 *$ & $1,00^{*}$ & 0,01 & 0,33 & 0,002 & 0,19 & $-0,23$ & $-0,19$ & - & & \\
\hline $\begin{array}{l}\text { RPCOSE } \\
R B C P S Y\end{array}$ & $-0,25$ & 0,15 & 0,03 & 0,15 & 0,24 & $0,39 *$ & $-0,61 *$ & 0,33 & $-0,005$ & $-0,34$ & 0,005 & $0,47 *$ & - & \\
\hline $\begin{array}{l}\text { ROSE } \\
B P S C Y\end{array}$ & 0,25 & $-0,15$ & $-0,03$ & $-0,15$ & $-0,24$ & $-0,39 *$ & $0,61 *$ & $-0,33$ & 0,005 & 0,34 & $-0,005$ & $-0,47$ & $-1,00 *$ & - \\
\hline
\end{tabular}

${ }^{*} \mathrm{P}<0,05$

$\mathrm{PCF}=$ carcaça fria $(\mathrm{kg}) ; \mathrm{PTT}=$ traseiro total $(\mathrm{kg}) ; \mathrm{PTE}=$ serrote $(\mathrm{kg}) ; \mathrm{PDI}=$ dianteiro $(\mathrm{kg}) ; \mathrm{PPTA}=$ ponta-de-agulha $(\mathrm{kg}) ; \mathrm{PPCOSE}=$ porção comestível do serrote $(\mathrm{kg})$; POSE =ossos do serrote $(\mathrm{kg}) ; \mathrm{RCF}=$ carcaça fria $(\%) ; \mathrm{RTT}=$ traseiro total $(\%) ; \mathrm{RTE}=$ traseiro especial $(\%) ; \mathrm{RDI}=$ dianteiro $(\%)$; RPT = ponta-de-agulha (\%); RPCOSE = porção comestível do serrote (\%); ROSE = ossos do serrote (\%)

CCW = cold carcass $(\mathrm{kg}) ; F O W=$ forequarter $(\mathrm{kg}) ; P S C W=$ pistola style cut $(\mathrm{kg}) ; H I W=$ hindquarter $(\mathrm{kg}) ; S R W=$ spare ribs $(\mathrm{kg}) ; R B C P S E W=$ retail beef cuts pystola stile $(\mathrm{kg}) ; B P S C W$ $=$ bone cuts pystola stile $(\mathrm{kg}) ; C C Y=$ cold carcass $(\%) ; F O Y=$ forequarter $(\%) ; C P S Y=$ pistola cut $(\%) ; H I Y=$ hindquarter $(\%) ; P R Y=s p a r e$ ribs $(\%) ; R B C P S E Y=$ retail beef cuts pystola stile $(\%)$; BPSCY = bone cuts pystola stile (\%). 
$(\mathrm{r}=0,97)$, em novilhos Red Angus abatidos em diferentes pesos. Esses autores encontraram também correlação semelhante para peso e rendimento de dianteiro $(r=0,43)$ e inferior para peso e rendimento de ponta-de-agulha $(r=0,81)$. Da mesma forma que neste estudo, esses autores não encontraram correlações significativas entre o rendimento de carcaça fria e os rendimentos de traseiro total, dianteiro e ponta-de-agulha.

Restle et al. (2002), avaliando características de carcaça de vacas de descarte terminadas em confinamento, observaram correlação positiva e significativa $(\mathrm{P}<0,05)$ entre o peso de carcaça fria e os pesos de dianteiro $(r=0,96)$, traseiro total $(\mathrm{r}=0,96)$ e ponta-de-agulha $(\mathrm{r}=0,94)$. Para rendimento de carcaça fria, constataram correlações positivas $(\mathrm{P}<0,05)$ para peso do dianteiro $(\mathrm{r}=0,51)$, entretanto, entre rendimento de carcaça fria, traseiro total e ponta-deagulha, não foi observada correlação significativa $(\mathrm{P}>0,05)$.

As correlações entre rendimento de traseiro total e dianteiro foram negativas $(\mathrm{r}=-1,00)$ e significativas $(\mathrm{P}<0,05)$, o que confirma o comportamento destas duas variáveis ilustrado na Figura 1. Do mesmo modo que neste estudo, Calixto (2004) observou correlação altamente significativa e negativa entre o rendimento de traseiro total e o de dianteiro $(r=-1,00)$.

\section{Conclusões}

Aos 150 dias de confinamento, Búfalos Murrah castrados provenientes de rebanho leiteiro, os pesos de carcaça fria, traseiro total, serrote e dianteiro são maiores que aos 75,100 ou 125 dias.

Períodos de confinamento entre 75 e 150 dias não afetam o rendimento de carcaça de bubalinos Murrah castrados provenientes de rebanho leiteiro.

O aumento do período de confinamento promove incrementos nos pesos de filé-mignon, contrafilé, fraldinha, coxão duro, coxão mole e lagarto e da porção comestível do corte serrote, porém, provoca redução nos rendimentos de alcatra + maminha, patinho e músculo traseiro e incremento do rendimento de fraldinha.

\section{Literatura Citada}

CALIXTO, M.G. Composição da carcaça e crescimento corporal de bubalinos jovens terminados em confinamento. Botucatu: Universidade Estadual Paulista. 2004. 46p. Dissertação (Mestrado em Zootecnia) - Universidade Estadual Paulista. Faculdade de Medicina Veterinária e Zootecnia, 2004.

COSTA, E.C.; RESTLE, J.; VAZ, F.N. et al. Características de carcaça de novilhos Red Angus superprecoces abatidos com diferentes pesos. Revista Brasileira de Zootecnia, v.31, n.1, p.119-128, 2002.

FATURI, C.; RESTLE, J.; BRONDANI, I.L. et al. Características de carcaça e da carne de novilhos de novilhos de diferentes grupos alimentados em confinamento com diferentes proporçõs de grão de aveis e grão de sorgo no concentrado. Revista Brasileira de Zootecnia, v.31, n.5, p.2024-2035, 2002.

FRANZOLIN, R.; SILVA, J.L. Níveis de energia na dieta de bubalinos em crescimento alimentados em confinamento. 2. Características de carcaça. Revista Brasileira de Zootecnia, v.30, n. 6, p.1880-1885, 2001.

JORGE, A.M.; ANDRIGHETTO, C. Características de carcaça de bubalinos. In: ZOOTEC, 2005, Campo Grande.Anais...Campo Grande: 2005. p.1-29.

JORGE, A.M.; ANDRighetTo, C.; CAliXto, M.G. et al. Características quantitativas da carcaça de bubalinos de três grupos genéticos terminados em confinamento e abatidos em diferentes estádios de maturidade. In: REUNIÃO ANUAL DA SOCIEDADE BRASILEIRA DE ZOOTECNIA, 40., 2003, Santa Maria. Anais... Brasília: Sociedade Brasileira de Zootecnia, 2003. (CD-ROM).

JORGE, A.M.; CALIXTO, M.G.; ANDRIGHETTO, C. et al. Effect of sexual condition and slaugheter weight on carcass traits from buffalo finished in feedlot. In: BUFFALO SYMPOSIUM OF AMERICAS, 1., 2002, Belém. Proceedings... Belém: Associação dos Criadores de Búfalos, 2002. (CD-ROM).

JORGE, A.M. Desempenho em confinamento e características de carcaça em bubalinos. In: SIMPÓSIO PAULISTA DE BUBALINOCULTURA, 1999, Jaboticabal. Anais... Jaboticabal: Funep, 1999. v.1, p.51-67.

JORGE, A.M.; FONTES, C.A.A.; SOARES, J.E. et. al. Características de carcaça de bovinos e bubalinos, abatidos em diferentes estádios de maturidade. Revista Brasileira de Zootecnia, v.26, n.5, p.1039-1047, 1997.

LUCHIARI FILHO, A. Pecuária da carne bovina. São Paulo: Limbife, 2000. 140p.

MACEDO, M.P.; BIANCHINI SOBRINHO, E. et al. Características de carcaça de bubalinos da raça mediterrâneo terminados em diferentes regimes alimentares. In: REUNIÃO ANUAL DA SOCIEDADE BRASILEIRA DE ZOOTECNIA, 37., 2000, Viçosa, MG. Anais... Viçosa, MG: Sociedade Brasileira de Zootecnia, 2000. p.1-3.

MATTOS, J.C.A.; NOGUEIRA, J.R.; OLIVEIRA, A.A.D. et al. Comparasion on carcass, meat cuts and some meat quality characteristis of buffaloes and of zebu In: CONGRESSO MUNDIAL DE CRIADORES DE BÚFALOS, 6., 1997, Caserta. Proceedings... Caserta: 1997. p.442-446.

NATIONAL RESEARCH COUNCIL - NRC. Nutrient requirements of beef cattle. 7.ed. Washington D.C.: National Academy Press, 1996. 242p.

PRESTON, T.R.; WILLIS, M.B. Intensive beef production. 2.ed. Oxford: Pergamon Press, 1974. 546p.

RESTLE, J.; PASCOAL, L.L.; FATURI, C. et al. Efeito do grupo genético e da heterose na características da quantitativas carcaça de vacas de descarte terminadas em confinamento. Revista Brasileira de Zootecnia, v.31, n.1, p.350-362, 2002.

RESTLE, J.; VAZ, F.N.; FEIJÓ, G.L.D. et al. Características de carcaça de bovinos de corte inteiros ou castrados de diferentes composições raciais Charolês x Nelore. Revista Brasileira de Zootecnia, v.29, n.5, p.1371-1379, 2000.

RESTLE, J.; VAZ, F.N. Machos não castrados para a produção de carne. Confinamento, pastagens e suplementação para a produção de bovinos de corte. Santa Maria: Universidade Federal de Santa Maria, 1999. p.215-231.

RODRIGUES, V.C.; ANDRADE, I.F.; FREITAS, R.T. et al. Rendimentos do abate e carcaça de bovinos e bubalinos castrados e inteiros. Revista Brasileira de Zootecnia, v.32, n.3, p.663-671, 2003.

STATISTICAL ANALISYS SYSTEM - SAS. User's guide: statistics. 4.ed. Version 6, Cary: 1993. v.2, 1686p.

VAZ, F.N.; RESTLE, J.; BRONDANI, I.L. et. al. Estudo da carcaça e da carne de bubalinos Mediterrâneo terminados em confinamento com diferentes fontes de volumoso. Revista Brasileira de Zootecnia, v.32, n.2, p.393-404, 2003. 